\title{
IONIC MASS TRANSFER IN CHANNEL ELECTRODES UNDER LAMINAR FLOW*
}

\author{
A. Palade de Iribarnet, S. L. Marchiano and A. J. Arvia \\ Departamento de Industrias, Facultad de Ciencias Exactas, Físicas y Naturales, \\ Universidad de Buenos Aires and División Electroquímica, Instituto Superior \\ de Investigaciones, Facultad de Ciencias Exactas, Universidad Nacional de \\ La Plata, La Plata, Argentina
}

\begin{abstract}
The rate of ionic mass transfer under a Poiseuille profile in channel electrodes involving inert zones has been studied. The electrolysis cell was vertically and horizontally placed, the working electrodes facing either upwards or downwards. An extension of Levich's solution for the convectivediffusion equation in a tube comprising an inert zone was applied. The experimental numerical coefficient lies $10 \%$ lower than the one theoretically derived.
\end{abstract}

Résumé-On a étudié la vitesse du transport de masse avec un profil de Poiseuille dans une cellule électrochimique en forme de canal, comprenant des zones inertes. La cellule fut placée verticalement ou horizontalement et les électrodes de travail dirigées vers le haut ou le bas. On a appliqué l'extension d'une solution de Levich pour l'équation de la diffusion convective d'une électrode tubulaire, avec une zone inerte. Le coefficient numérique de l'équation expérimentelle est 10 pour cent moins que la valeur déduite théoriquement.

Zusammenfassung-Es wurde die Geschwindigkeit des Ionen-Massen-Transportes mit Poiseuilleschen Profil in Kanal-Elektroden mit inerten Zonen untersucht. Die Elektrolysenzelle wurde vertikal und horizontal eingesetzt, wobei die Elektroden entweder nach oben oder nach unter gerichtet waren. Es wurde eine modifizierte Lösung der Lewitsch-Gleichung für das Modell einer konvektiven Diffusion in einer röhrenartigen Elektrode mit einer inerten Zone angewandt. Der experimentell bestimmte numerische Koeffizient liegt $10 \%$ niedriger als der theoretisch abgeleitete.

\section{INTRODUCTION}

THE STUDY of ionic mass transfer with electrodes that form the walls of a duct is of particular interest in electrochemistry for two main reasons. Firstly, the design of such a cell is in principle suitable for hydrodynamic voltammetry, and secondly, it can be successfully applied to continuous electrochemical processes. For these reasons theoretical as well as experimental papers have been published concerning ionic mass transfer in electrodes forming ducts. ${ }^{1-7}$

The rate of mass transfer in a channel-type cell is modified both by the entrance length, involving the region where the hydrodynamic profile is being developed, and by the existence of portions of the surface that are inactive from the standpoint of the occurring reaction. Consequently, their influence is reflected in the rate equations derived by assuming certain momentum and mass transfer mechanisms in the zones adjacent to the reacting surface.

The mass-transfer rate equations for the plane plate, annular and channel electrodes under the laminar flow regime, with or without an inert zone, have been solved by Levich. ${ }^{8}$ Equivalent equations for the plane plate were also obtained by Wranglén, ${ }^{9}$ following the method of von Kárman. ${ }^{10}$ Lately, Matsuda ${ }^{11}$ obtained mass-transfer rate equations for electrodes forming ducts and involving a Poiseuille profile, although inert regions were not considered in the rate equations.

The results obtained with a rectangular duct electrolysis cell comprising an inert zone are reported in the present article.

* Manuscript received 13 September 1969.

† Present address: Chemical Engineering Department, University of Toronto, Toronto, Canada. 


\section{EXPERIMENTAL TECHNIQUE}

The electrolysis cell forms a duct of rectangular section; its scheme is shown in Figs. 1 and 2. Two different equivalent diameters are employed in the electrolysis cell

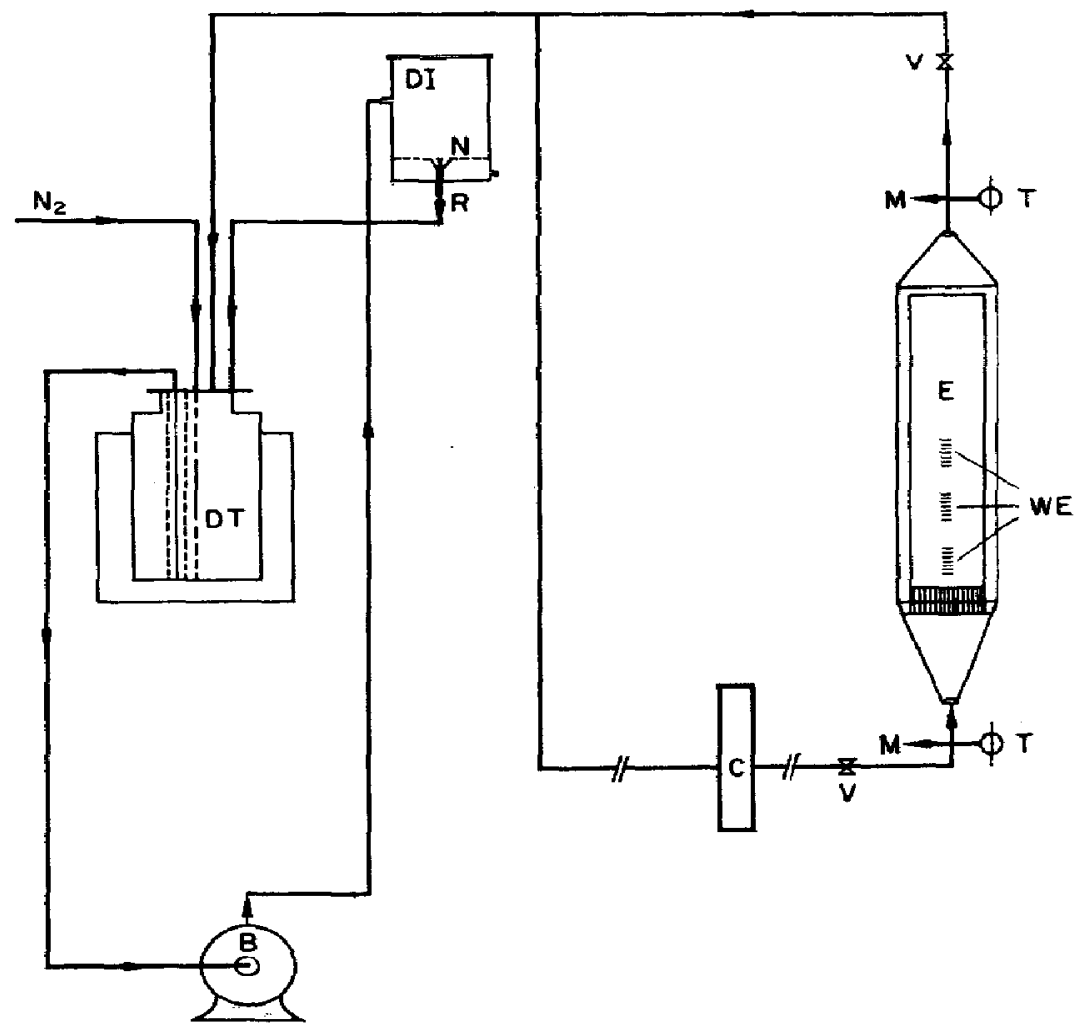

FIG. 1. Scheme of the hydrodynamic circuit.

$E$, electrolysis cell; WE, working electrodes; $M$, sampling valve; $T$, temperature recorder; V, valves; DI, intermediate reservoir; DT, main thermostated reservoir; $C$, flowmeter; $N$, levelling funnel; $B$, centrifugal pump.

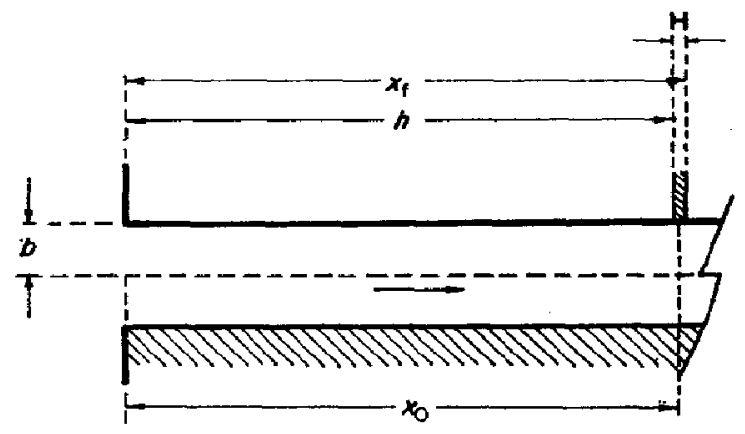

Fig. 2. Diagram of the different lengths involved in the equations.

$(1.38$ and $1.50 \mathrm{~cm})$ corresponding to the rectangular sections employed: $5 \mathrm{~cm} \times 0.8$ $\mathrm{cm}$ and $13 \mathrm{~cm} \times 0.8 \mathrm{~cm}$. The inlet and outlet of the cell are designed as divergent and convergent channels respectively, filled with Raschig glass rings to produce a uniform flow. The cell is used in three different positions involving (i) horizontal 
working electrodes facing downwards (ii) horizontal working electrodes facing upwards and (iii) vertical working electrodes. The cell is made with the working electrodes placed in such a way as to avoid any edge effect on the active regions except that of the existing inert zones.

The entrance length corresponding to the duct cell was calculated with Schlichting's equation ${ }^{12}$

and through Sparrow's equation ${ }^{\mathbf{1 3 . 1 4}}$

$$
L=0.01 d R e,
$$

$$
L=0.0065 d R e,
$$

where $L$ is the entrance length, $d$ the equivalent diameter and $R e$ the Reynolds number given in terms of $d$. By plotting $L$ against $\bar{D}$, where $\bar{V}$ is the average fluid velocity in the duct, two straight lines corresponding to (1) and (2) respectively are obtained, which divide the $L-\bar{V}$ plane into two regions corresponding either to a Poiseuille profile or to a region where the hydrodynamic profile is being developed. This plot, shown in Fig. 3, permits us to decide the hydrodynamic conditions prevailing on each working electrode.

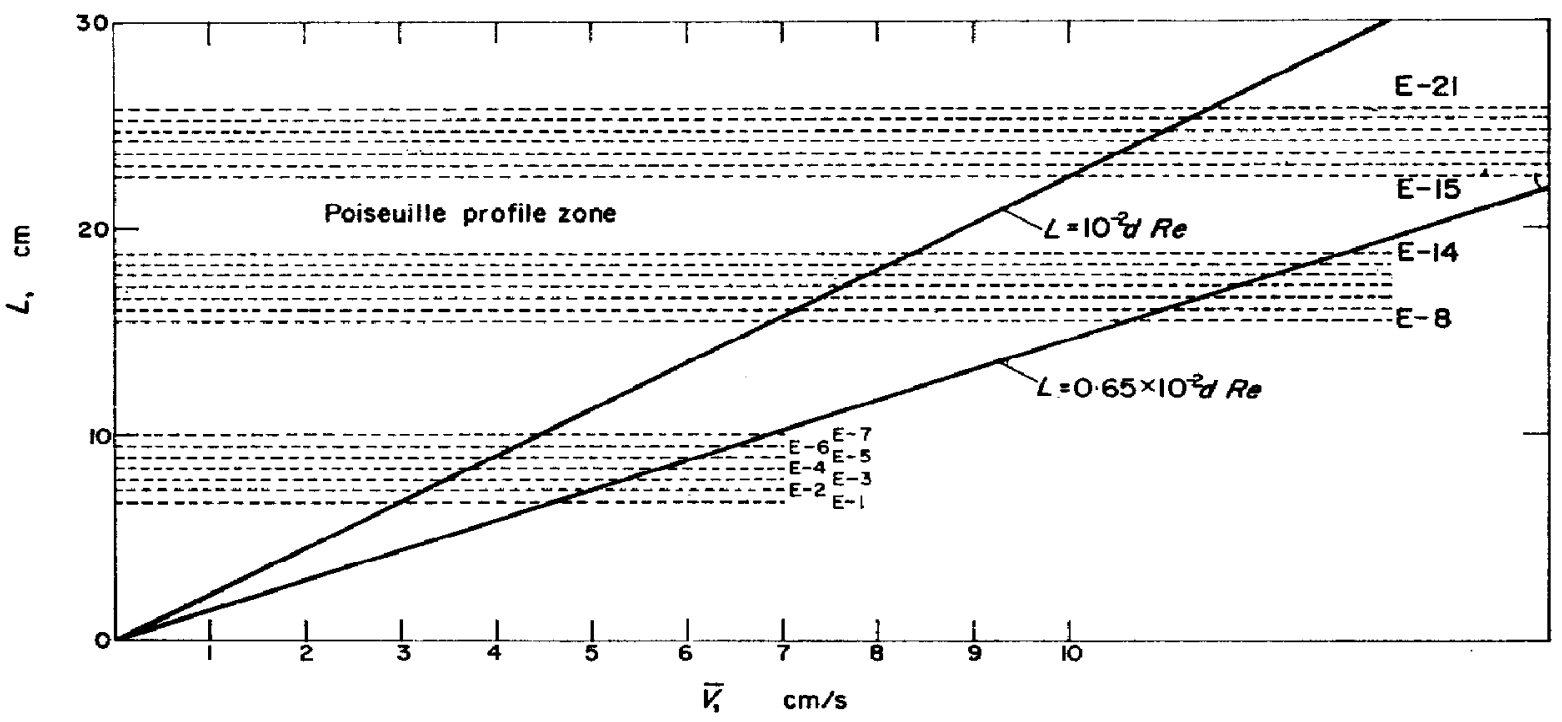

Fig. 3. Plot of the entrance length $L$ vs average flow rate $\nabla$, according to Schlichting's and to Sparrow's equations.

Positions of the electrodes are indicated in the figure. Straight lines are calculated assuming $\nu=10^{-2} \mathrm{~cm}^{2} / \mathrm{s}$.

Equimolar solutions of potassium ferro- and ferricyanide $(0.1,0.05$ and $0.025 \mathrm{M})$ in $2 \mathrm{M}$ sodium hydroxide were used. The electrolyte solution flows in the hydrodynamic circuit at a constant temperature being pumped continuously from a reservoir with a capacity of about 121 . placed in a thermostal by means of an acrylic resin centrifugal pump mounted on a damping structure to avoid vibrational interference in the electrochemical processes. The flow was regulated by means of a set of valves and kept constant with the aid of an intermediate reservoir located in the hydrodynamic circuit. The flow rate was measured with a set of calibrated Pyrex flowmeters 
covering the whole range of velocities employed in the experiments. The solution flowed through a screen with holes of $0.3 \mathrm{~cm}$ diameter to eliminate any turbulence in the electrochemical cell entrance, and was continuously saturated with purified nitrogen.

Electrolytic nickel was employed for the electrodes. Three sets of seven working electrodes of rectangular shape $1 \times 0.15 \mathrm{~cm}^{2}$ were placed at the centre of one of the large cell walls. The location of each electrode in the rectangular duct is deduced from Fig. 1 and 3. The counter-electrode was also of nickel and located just in front of a working electrode. Its area was $75 \mathrm{~cm}^{2}$. The location of these electrodes assured a good current distribution. The nickel electrodes were activated prior to the experiments, by making them cathodes in a $0.5 \mathrm{~N}$ sodium hydroxide solution at a cd of $20 \mathrm{~mA} / \mathrm{cm}^{2} 1 \mathrm{~h}$ with a nickel anode.

The electrochemical reaction occurring at the working electrodes is represented by

$$
\mathrm{Fe}(\mathrm{CN})_{6}^{3-}+\mathrm{e} \rightleftarrows \mathrm{Fe}(\mathrm{CN})_{8}^{4-} \text {. }
$$

The diffusion coefficient of the ions involved in the reaction, and the density and viscosity of solutions required in the calculations, are reported in the literature. ${ }^{15}$

Conventional electrolysis and measurement circuitries, as reported in earlier work, were used. ${ }^{15.16}$ The limiting current was read at a constant potential and different flow-rates. Temperatures both at the cell inlet and outlet were simultaneously recorded and a sample of the solution was separated to evaluate its concentration. Experiments with the electrolyte at rest were also made to establish the influence of natural convection.

\section{RESULTS}

The limiting cds obtained at different flow rates were processed with the aid of a computer in the usual way. The average mass transfer rate constant, $k$, was obtained with

$$
k=\frac{I_{L}}{z F A C_{0}},
$$

where $I_{\mathrm{L}}$ is the limiting current, $A$ the electrode area, $C_{0}$ the bulk concentration of the reacting ion, and $z$ and $F$ have the usual meanings.

A $\log / \log$ plot of the average rate constant, $\hat{k}$, against the average fluid velocity $\nabla$, yields a set of straight lines as shown in Figs. 4-6, each line corresponding to a particular electrode. From those plots it is concluded that $k$ is proportional to the 1/3th power of the average velocity for all the electrodes in the different positions.

The usual way of expressing dimensionless correlations for mass transfer in ducts is by means of Sherwood $(S h)$, Schmidt $(S c)$ and Reynolds $(R e)$ numbers, the latter given in terms of the equivalent diameter. The dimensionless numbers are defined as

$$
S h=\frac{k d}{D_{1}} ; \quad \operatorname{Re}=\frac{\bar{\nabla} d}{\nu} \quad \text { and } \quad S c=\frac{y}{D_{1}},
$$

where $D_{1}$ is the diffusion coefficient of the reacting species and $\nu$ is the kinematic viscosity.

Then, by plotting $S h$ vs $(\operatorname{Re} . S c)^{1 / 3}(d / H)^{1 / 3}$, the experimental data, independently 


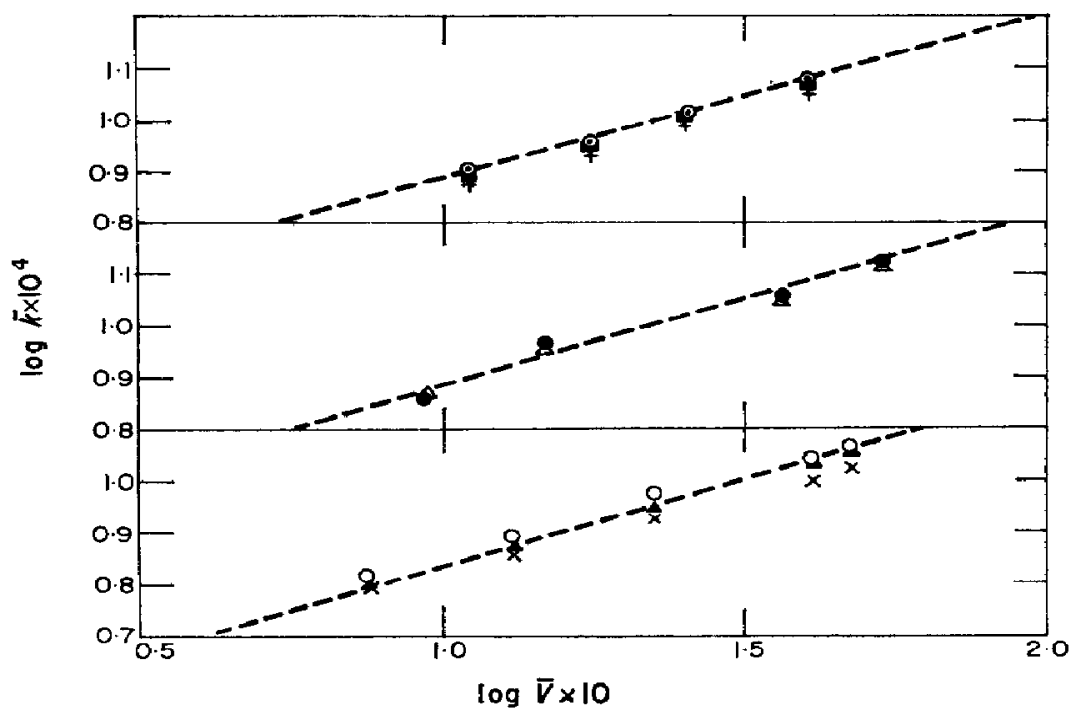

Frg. 4. $\log / \log$ plot of $k$ os $D$, for the cell horizontally placed with cathodes facing
O, electrode 1 ;
A, electrode 2 ;
$\times$, electrode 6 ;
, electrode 10;
$\triangle$, electrode 12;
$\odot$, electrode 15;
$\square$, electrode 18 ;
+ , electrode 21 ;

upwards.

The slope of the dotted lines is $\frac{1}{3}$. Equivalent diameter $1.5 \mathrm{~cm}$.

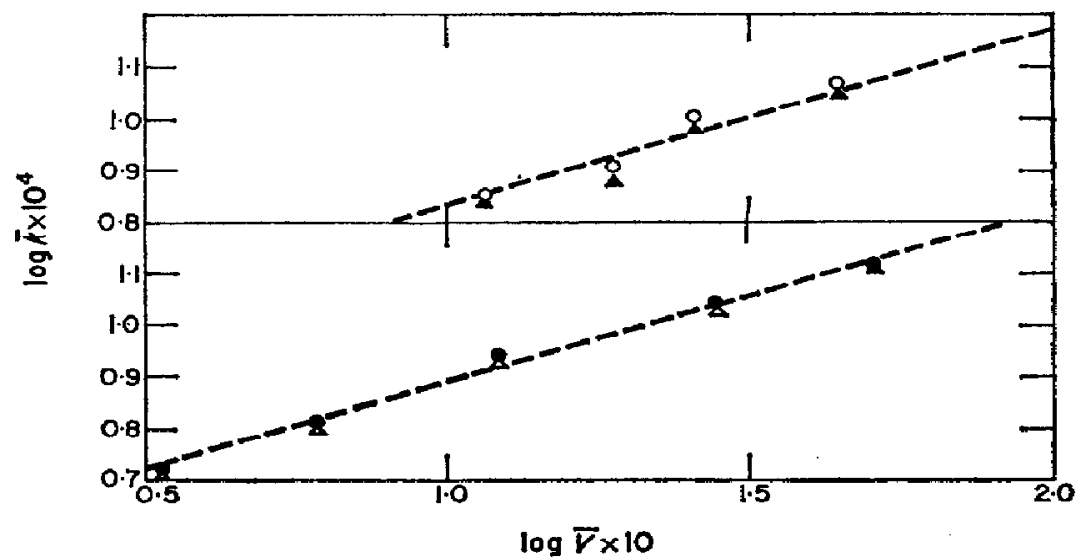

FIG. 5. Log/log plot of $k$ vs $P$, for the cell horizontally placed with the cathodes facing downwards
, electrode 8;
$\triangle$, electrode 12 ;
O, electrode 15;
$A$, electrode 21 ;

The slope of the dotted lines is $\frac{1}{8}$. Equivalent diameter $1.5 \mathrm{~cm}$.

of the electrode position, lie on a straight line which goes through the origin of coordinates as shown in Fig. 7. The experimentally dimensionless rate equation is

$$
S h=1 \cdot 43 R e^{1 / 3} S c^{1 / 3}\left(\frac{d}{H}\right)^{1 / 3}
$$

$H$ is the electrode height as indicated in Fig. 2. A larger dispersion of results occurs when the length of the inert zone, $h$, increases. 


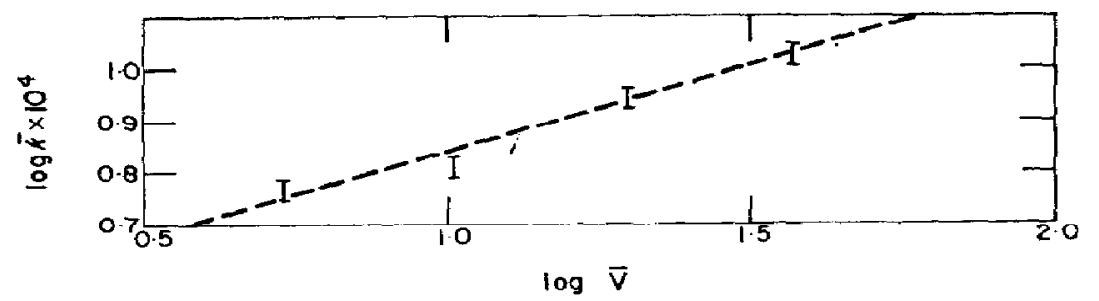

Fig. 6. Log/log plot of $k$ os $V$ for the cell vertically placed.

Data correspond to electrodes 1-7. The slope of the dotted lines is $t$. Equivalent diameter $1.5 \mathrm{~cm}$.

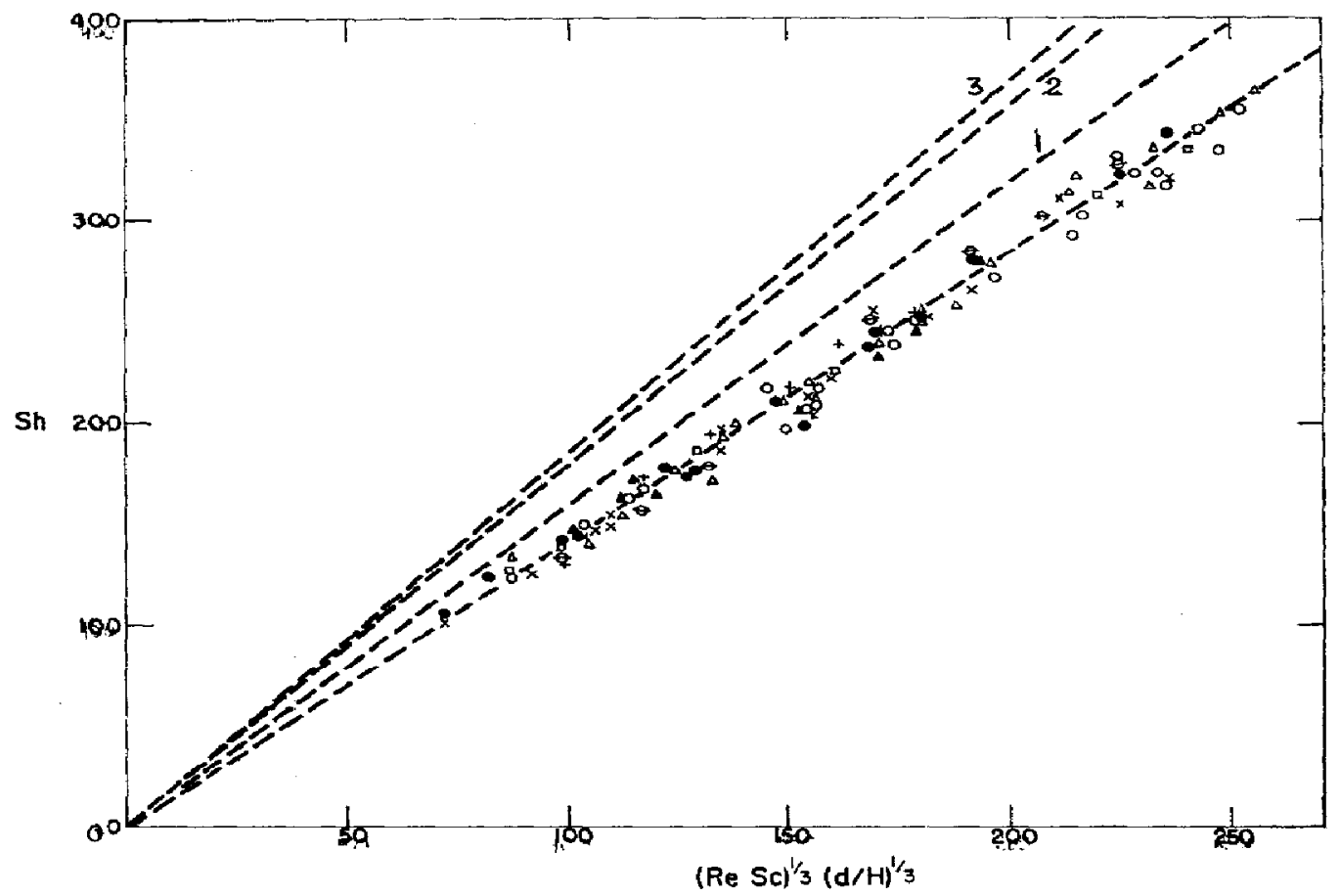

Fig. 7. Plot of the general correlation. The dotted lines 1,2 and 3 correspond respectively to Levich's, Matsuda's, and Norris and Streid's epuations.

An interesting effect is visualized when the average rate constant is plotted against the distance measured along the direction of the flow from the duct origin and the initial edge of the electrode. The fluctuations of the rate constant, as seen in Figs. 8-10, depends on $h$ and the position of the cell. For a cell horizontally placed with the working electrode facing upwards, the fluctuations are less marked than for the case of horizontal electrodes facing downwards. For low values of $\bar{D}$ in both cases the average rate constant approaches a steadier value as $h$ increases. The same behaviour is found with the cell vertically placed, although it is much less significant than for electrodes horizontally placed.

\section{DISCUSSION}

Before discussing the results in terms of the theoretical rate equations, it is important to decide whether there is any effect of free convection or not. For the purpose the criterion described by Tobias and Hickman ${ }^{5}$ was applied. When the ionic mass 


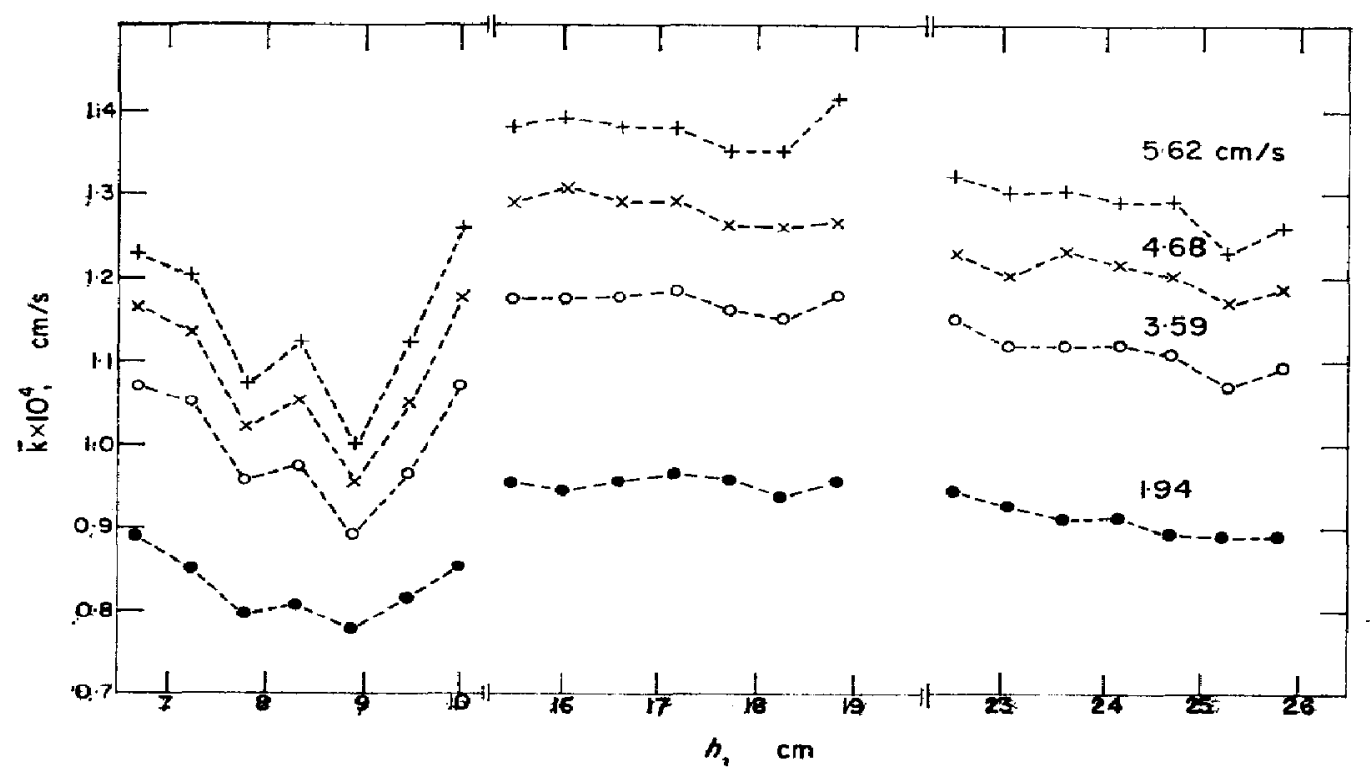

FIG. 8. Dependence of the average rate constant, $k$, on the position of the electrode for different fluid velocities.

Cell horizontally placed with electrodes facing upwards. Equivalent diameter $1.5 \mathrm{~cm}$.

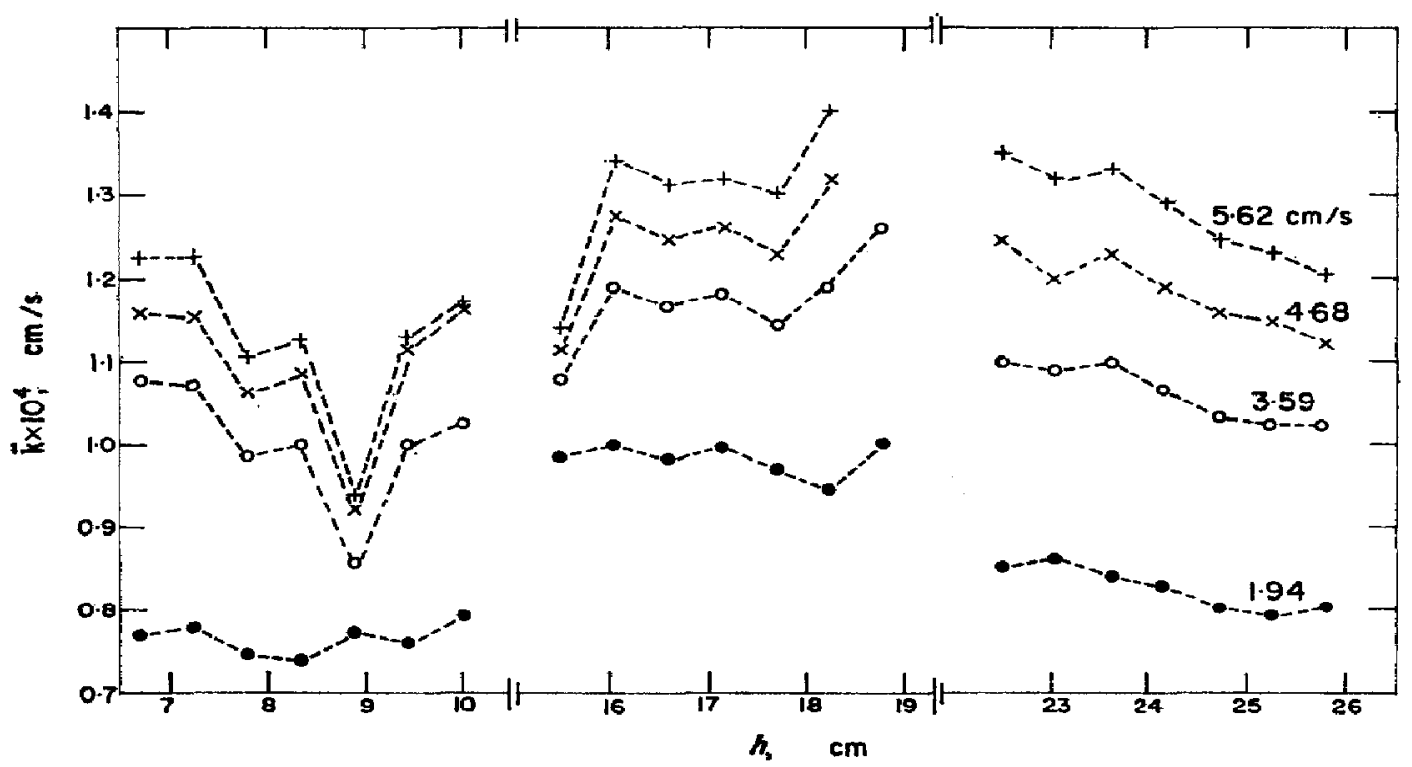

FIG. 9. Dependence of the rate constant, $k$, on the position of the electrode for different fluid velocities.

Cell horizontally placed with electrodes facing downwards. Equivalent diameter 1.5 cm. 


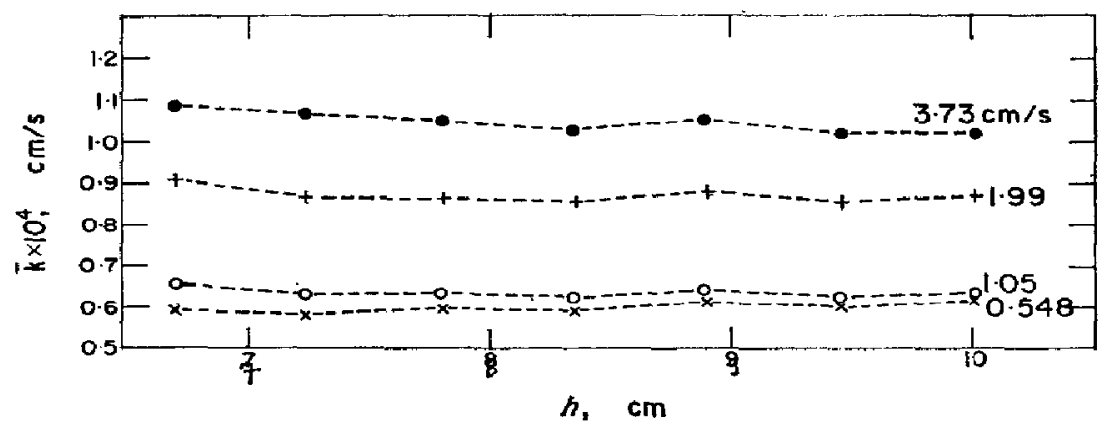

Fig. 10. Dependence of the rate constant, $k$, on the position of the electrode for different fluid velocities.

Cell vertically placed. Equivalent diameter $1.5 \mathrm{~cm}$.

transfer is controlled by free convection, the equation proposed by Fenech and Tobias ${ }^{17}$ is obeyed, but if the forced laminar flow is the controlling convectional mode, the equation derived by Norris and Streid ${ }^{4}$ is fulfilled. By using both equations a function of the type $\mathrm{g}(\mathrm{Gr} . S c)=\mathrm{f}(\operatorname{Re} . S c)$ is obtained which defines the limits of flow regime in which the superimposed convective processes both play important roles in mass transfer. ${ }^{5}$

On applying this criterion to the experimental results, they fall into the second region. Therefore, if the Poiseuille profile is fully developed, as occurs with most of the working electrodes used in the present experiments, an equation of the form proposed by Norris and Streid should be obeyed.

The discussion of the results must be centered in the following two aspects of the problem: the interpretation of the experimental mass-transfer rate in terms of the theoretical equation derived from the exact solutions of the convective-diffusion differential equation for ducts, and the cause of the rate constant fluctuations with electrode position.

A theoretical rate equation for ionic mass transfer on electrodes located at a tube wall was derived by Levich ${ }^{8}$ for a laminar flow when no inert zone existed, assuming that the flow is upward and that the hydrodynamic boundary layer is smaller than the diffusion boundary layer. In the region where the hydrodynamic profile is fully developed the following rate equation for the total flux, $J_{\max }$, is obtained,

$$
J_{\max }=2 \cdot 01 \pi C_{0} D_{1} R\left(\frac{V_{0} x^{2}}{D_{1} R}\right)^{1 / 3},
$$

where $V_{0}$ is the maximum velocity in the $x$-direction and $R$ is the radius of the tube. When there is an inert zone of length $h$, the ionic mass transfer rate towards the surface increases, due to the tangential transport of the reacting species. Then, the rate equation for the average flux, $\bar{J}_{\max }$, becomes:

$$
j_{\max }=0.67 C_{0} D_{i}\left(\frac{V_{0}}{D_{1} R}\right)^{1 / 3}\left(\frac{1}{x-h}\right)^{1 / 3}
$$

A general theoretical treatment of the ionic mass transfer in ducts under a Poiseuille profile without contribution of inert zone was made by Matsuda. ${ }^{11}$ The general 
equation for the maximum flux $J_{\max }$ is

$$
J_{\max }=1 \cdot 282 A C_{0} D_{i}^{2 / 3}(D)^{1 / 3}(R . H)^{-1 / 3},
$$

where $A$ is the electrode geometrical area.

Let us derive from (7) and (8) the dimensionless rate equations involving as characteristic length the equivalent diameter, for a channel comprising an inert zone. For this case, the velocity components $v_{x}$ and $v_{y}$ in the $x$ - and $y$-directions respectively, defining the hydrodynamic profile, are given by

$$
v_{x}=\frac{3}{2} V_{0}\left(\frac{y}{b}\right)\left(2-\frac{y}{b}\right),
$$

and

$$
v_{v}=\mathbf{0}
$$

The maximum flow velocity, $V_{0}$ is

$$
V_{0}=\frac{3}{2} V
$$

and the distance $R$ must be given in terms of the half-width of the channel, $b$,

$$
R=\frac{4}{3} b
$$

From (7), (11), and (12), the resulting dimensionless equation is

$$
j_{\max }=0.695 C_{0} D_{\mathrm{i}}\left(\frac{\vec{D}}{D_{\mathrm{i}} b}\right)^{1 / 3}\left(\frac{1}{x-h}\right)^{1 / 3}
$$

The total maximum flux, $J_{\max }$, is obtained by integrating (13) over the electrode surface

$$
J_{\max }=1 \cdot 035 C_{0} D_{1}\left(\frac{\bar{D}}{D_{\mathrm{i}} b}\right)^{1 / 3} H^{2 / 3},
$$

where $H=x_{f}-h$. After rearranging this equation in terms of dimensionless numbers, the average rate equation is

$$
S h=1 \cdot 035(R e S c)^{1 / 3}(d / H)^{1 / 3}(d / b)^{1 / 3} .
$$

By repeating the same procedure starting from (8), the average dimensionless rate equation becomes

$$
S h=1 \cdot 16(R e S c)^{1 / 3}(d / H)^{1 / 3}(d / b)^{1 / 3} .
$$

Finally, let us write Norris and Streid's equation in the same form, to compare with (15) and (16). It is,

$$
S h=1 \cdot 85(\operatorname{Re} S c)^{1 / 3}(d / H)^{1 / 3} \text {. }
$$

Taking into account that the ratio $(d / b)=3.75$ for $d=1.50 \mathrm{~cm}$ it is possible to compare graphically the three above rate equations, as shown in Fig. 7 . The experimental results satisfy the general form of the theoretical equations, being closer to the numerical coefficient derived from Levich's equation, although the experimental one is on an average $10 \%$ lower. 
As far as the fluctuations of the rate constants with distance along the flow direction are concerned, no quantitative interpretation can be given, as this effect is not considered in the rate equations. Although the effect is small it shows a systematic trend beyond the error of the experimental measurements. It is interesting to emphasize that the same behaviour has been reported by Tobias and Hickman, ${ }^{5}$ who observed a similar effect with copper electrodes facing upwards in a channel cell. This aspect of the problem deserves further study.

Acknowledgement-This work was partially supported by the Consejo Nacional de Investigaciones Cientfficas y Técnicas of Argentina. S. L. M. participates in the project under a contract of the Chemical Engineering Dept. of the University of La Plata.

\section{REFERENCES}

1. J. Lêvêqu, An. Mines 13, 201 (1928).

2. C. S. Lin, E. B. Denton, H. S. Gaskill and G. L. Putnam, Ind. Engng Chem. 43, 2136 (1951).

3. J. C. BazÁn and A. J. Arvia, Electrochim. Acta 9, 17 (1964).

4. R. H. NorRIS and D. D. STREID, Trans. Am. Soc. Mech. Engrs 62, 525 (1940).

5. C. W. Tonlas and R. G. Hickman, Z, phys. Chem. 229, 145 (1965).

6. H. Gerischer, I. MAtTes and R. BRAun, J. electroanal. Chem. 10, 553 (1965).

7. T. K. Ross and A. A. WRAGG, Electrochim. Acta 10, 1093 (1965).

8. B. Levich, Physicochemical Hydrodynamics, 2nd edn. Prentice-Hall, Englewood Cliffs, New Jersey (1962).

9. G. Wranglén and O. Nilsson, Electrochim. Acta 7, 111 (1962).

10. T. von Kárman, Z. Angew. Math. Mech. 1, 233 (1921).

11. H. MATsuda, J. electroanal. Chem. 15, 325 (1967).

12. H. Schlichting, Boundary Layer Theory. McGraw-Hill, New York (1955).

13. E. M. Sparrow, NACA Tech. Note 3331 (1955).

14. L. S. HAN, J. appl. Mech. 82, 403 (1960).

15. J. C. BAzÁN and A. J. ARVIA, Electrochim. Acta 10, 1025 (1965).

16. S. L. Marchiano, A. J. Arvia and J. A. Bolzan, An. Asoc. Qutm. Argent. 54, 157 (1966).

17. E. J. Fenech and C. W. Tobias, Electrochim. Acta 2, 311 (1960). 